\title{
ANÁLISIS DE VARIABLES MORFO-ANATÓMICAS EN TEPHROCACTUS (CACTACEAE), SU CORRELACIÓN CON NIVELES DE PLOIDÍA Y MAPEOS EN SU FILOGENIA
}

\author{
ANALYSES OF MORPHO-ANATOMIC VARIABLES IN TEPHROCACTUS \\ (CACTACEAE): CORRELATION WITH PLOIDY LEVELS AND MAPPING IN ITS \\ PHYLOGENY
}

Ivana Di Dio ${ }^{1}$, Laura B. Stiefkens ${ }^{1,2}(\mathbb{0})$ \& M. Laura Las Peñas ${ }^{1,3 *}(\mathbb{0}$

1. Instituto Multidisciplinario de Biología Vegetal (IMBIV, UNCCONICET), Facultad de Ciencias Exactas, Físicas y Naturales, Universidad Nacional de Córdoba, Córdoba, Argentina

2. Cátedra de Morfología Vegetal, Fac. Cs. Exactas, Físicas y Nat., UNC. 3. Cátedra de Genética, Fac. Cs. Exactas, Físicas y Nat., UNC.

*lauralaspenas@unc.edu.ar

Citar este artículo

DI DIO, I., L. B. STIEFKENS \& $M$. L. LAS PEÑAS. 2022. Análisis de variables morfo-anatómicas en Tephrocactus (Cactaceae), su correlación con niveles de ploidía y mapeos en su filogenia. Bol. Soc. Argent. Bot. 57: 9-24.

DOI: https://doi. org/10.31055/1851.2372.v57. n1.34773

Recibido: 11 Sep 2021

Aceptado: 4 Dic 2021

Publicado en línea: 20 Feb 2022

Publicado impreso: 31 Mar 2022

Editora: Ana María Gonzalez iD

ISSN versión impresa 0373-580X

ISSN versión on-line 1851-2372

\section{SUMMARY}

Background and aims: Tephrocactus is a genus of Cactaceae belonging to the Opuntioideae subfamily, with most of its species endemic to Argentina. It comprises bushes with lax branches formed by globose joints, which are often fragile and detach generating new plants. Clonal reproduction is associated with the occurrence of high ploidy levels in the genus. The aim of this work was to compare morpho-anatomical traits of the epidermis and underlying tissues of Tephrocactus taxa with different ploidy levels $(2 n=22,44,77,88,242$ and 319$)$ and to evaluate them in a phylogenetic context. M\&M: The epidermis and underlying tissues of specimens were studied by means of classical histological techniques. The morpho-anatomical variables were statistically compared and mapped on the phylogeny of the genus.

Results: The stomatal frequency, the frequency of ordinary epidermal cells, the stomatal index, and the stomata length were determined and the underlying tissues (hypodermis) were analyzed with special reference to the shape, frequency and arrangement of druses. All the variables studied showed statistically significant differences among taxa. A positive relationship was found between ploidy levels and size of all types of epidermal cells and druses.

Conclusions: The common ancestor of the group would have small stomata, an intermediate frequency of ordinary epidermal cells, and druses in their hypodermis. The characteristics of the epidermis and underlying tissues correlate with the level of ploidy in the Tephrocactus taxa studied.

\section{KEY WORDS}

Cactaceae, morpho-anatomy, mapping morpho-anatomy, ploidy level, Tephrocactus.

\section{RESUMEN}

Introducción y objetivos: Tephrocactus es un género de Cactaceae perteneciente a la subfamilia Opuntioideae, con la mayoría de las especies endémicas de Argentina. Comprende matas con ramas laxas, formadas por artejos globosos, que muchas veces se desprenden fácilmente y generan nuevas plantas. La reproducción clonal está asociada a la ocurrencia de altos niveles de ploidía en el género. El objetivo de este trabajo fue comparar caracteres morfo-anatómicos de la epidermis y tejidos subyacentes de taxones de Tephrocactus con distintos niveles de ploidía ( $2 n=22,44$, $77,88,242$ y 319) y evaluar dichos caracteres en un contexto filogenético.

M\&M: Se estudiaron la epidermis y tejidos subyacentes de taxones de Tephrocactus mediante el uso de técnicas histológicas clásicas. Se compararon estadísticamente las variables morfo-anatómicas y se mapearon en la filogenia del género.

Resultados: Se determinaron la frecuencia estomática, la frecuencia de células epidérmicas propiamente dichas, el índice estomático, la longitud de los estomas y se analizaron los tejidos subyacentes con especial referencia a la forma, frecuencia y disposición de drusas. Todas las variables estudiadas mostraron diferencias estadísticamente significativas entre los taxones. Se observó una relación positiva entre niveles de ploidía y tamaño de todos los tipos de células epidérmicas y de las drusas.

Conclusiones: El ancestro común del grupo tendría estomas pequeños, una frecuencia de células epidérmicas propiamente dichas intermedia y drusas en su hipodermis. Las características de la epidermis y tejidos subyacentes se correlacionan con el nivel de ploidía en los taxones de Tephrocactus estudiados.

\section{Palabras clave}

Cactaceae, mapeos morfo-anatómicos, morfo-anatomía, niveles de ploidía, Tephrocactus. 


\section{INTRODUCCIÓN}

La familia Cactaceae Juss. incluye cerca de 1400 especies distribuidas desde Canadá hasta la Patagonia, siendo México el mayor centro de diversificación (Bravo-Hollis \& Scheinvar, 1999; Mandujano et al., 2002; Hunt et al., 2006). Los cactus han evolucionado para hacer frente a condiciones ambientales que otras plantas no podrían soportar; normalmente están sujetos, en algún momento de su desarrollo, a estrés por sequía y/o temperaturas extremas. Su estrategia de supervivencia radica en una serie de características morfológicas y en la fotosíntesis de tipo CAM (metabolismo ácido de las crasuláceas; Anderson, 2001; Herrera Martínez et al., 2015).

La familia es monofilética e incluye cuatro subfamilias: Cactoideae Eaton., Maihuenioideae Fearn, Opuntioideae Burnett y Pereskioideae Engelm. (Anderson, 2001; Hernández-Hernández et al., 2011). Opuntioideae, al contrario de Cactoideae, ha recibido relativamente poca atención por parte de especialistas y aficionados. Esto tal vez sea debido a su falta de atractivo como ornamentales y a sus molestos gloquidios (espinas foliares delgadas y poco visibles que se desprenden fácilmente de la planta) (Kiesling, 1984; Ritz et al., 2012). Solo dentro del género Opuntia, la especie $O$. ficus-indica, se cultiva en todo el mundo por sus frutos y para forraje (Nobel, 2002).

Dentro de la subfamilia Opuntioideae, el género Tephrocactus Lem. comprende plantas con ramas laxas, formadas por varios artejos superpuestos, de forma globosa hasta cilíndrica, muchas veces con las articulaciones frágiles. Las areolas están en criptas, con fascículos de gloquidios rojizos o blanquecinos, además de las espinas (Kiesling, 1984). Se distribuyen principalmente en la Argentina, en las provincias de Salta, Catamarca, oeste de Tucumán, La Rioja, Santiago del Estero, Córdoba, San Juan, San Luis y Mendoza. Estas plantas crecen en laderas más o menos suaves o en llanuras pedregosas o arenosas muy secas, entre los 500 y 2500 m s.n.m. (Kiesling, 1984; Anderson, 2001). El número de especies incluidas en el género, varía según los autores de siete a 12 (Kiesling, 1984; Hunt et al., 2006; Ritz et al., 2012). Recientemente, Las Peñas et al. (2019), publicó una filogenia, usando marcadores moleculares y morfológicos, donde concluyeron que el género estaría formado por 12 especies T. alexanderi (Britton \& Rose) Backeb., T. aoracanthus (Lem.) Lem., T. articulatus (Pfeiff.) Backeb., T. bonnieae (D.J.Ferguson \& R. Kiesling) Stuppy, T. geometricus (A. Cast.) Backeb., T. halophilus (Speg.) Backeb., T. molinensis (Speg.) Backeb., T. nigrispinus (K.Schum.) Backeb., T. paediophilus (A.Cast.) F.Ritter, T. recurvatus (Gilmer \& Thomas) Hunt \& Ritz, T. verschaffeltii (F.A.C.Weber) Hunt \& Ritz y T. weberi (Speg.) Backeb.

Con respecto a las características morfoanatómicas de la epidermis de Tephrocactus, solo se conocen descripciones de su aspecto a simple vista o bajo lupa binocular. La misma se describe opaca y rugosa, de color grisáceo verdosa (el nombre genérico deriva de la palabra griega: tephra, "ceniza", refiriéndose al color de la planta, Kiesling, 1984). Además, en los ejemplares secos puede advertirse el fácil desprendimiento de una capa de cera (Kiesling, 1984). El conocimiento de la estructura del aparato estomático, la cutícula, la epidermis y los estratos subepidérmicos poseen, no sólo importancia taxonómica, sino que además revelan, el grado de especialización alcanzado por estas plantas, en su adaptación al ambiente árido o semiárido en que se desarrollan (Di Fulvio, 1976, Gibson \& Nobel, 1986). Sin embargo, no existen antecedentes de estudios de la epidermis y tejidos subyacentes en Tephrocactus. Tampoco hay reportes de parámetros como frecuencia estomática, frecuencia de células epidérmicas propiamente dichas e índice estomático para estas especies. Por otro lado, una gran variedad de cactus, particularmente los de la subfamilia Opuntioideae, se reproducen asexualmente de manera habitual al deshacerse de las articulaciones del tallo que producen raíces adventicias y forman nuevos individuos (Anderson, 2001).

En ambientes extremos la replicación agámica resulta ser muy útil y exitosa, ya que los nuevos individuos poseen estructuras maduras tanto desde el punto de vista fisiológico como morfológico, además de zonas meristemáticas activas (areolas) que permiten la emisión de raíces adventicias (Almirón \& Martínez Carretero, 2013). La reproducción clonal está asociada con la incidencia de poliploidía en plantas con flores (Baldwin \& Husband, 2013). El número básico aceptado para la familia Cactaceae es $\mathrm{x}=11$, siendo la principal variación existente la poliploidía (Pinkava, 2002; 


\section{Ivana Di Dio et al. - Morfo-anatomía en Tephrocactus y su correlación con niveles de ploidía}

Las Peñas et al., 2017; 2019). Los estudios citológicos han demostrado que los poliploides son comunes en la subfamilia Opuntioideae (Pinkava, 2002; Las Peñas et al., 2017; 2019) con los niveles más altos en los miembros sudamericanos (incluyendo Tephrocactus; Pinkava et al., 1985, Las Peñas et al., 2019). A pesar de su ocurrencia generalizada, el efecto directo de la poliploidía en el éxito evolutivo de una especie aún es en gran parte desconocido (Madlung, 2013). Las Peñas et al. (2019) observaron una gran variabilidad de los niveles de ploidía en el género Tephrocactus con $2 \mathrm{n}=22,44,77,88,242,319$. Durante mucho tiempo, los poliploides se han estudiado por sus diferencias morfológicas, fisiológicas y de desarrollo para encontrar evidencias que pudieran explicar las observaciones de mayor resistencia al estrés (Madlung, 2013). Por ejemplo, Melaragno et al. (1993), reportan un mayor tamaño de las células epidérmicas y los estomas en poliploides de Arabidopsis (Brassicaceae). Además, la frecuencia estomática y la longitud de las células oclusivas se han usado a menudo como marcadores morfológicos para identificar los niveles de ploidía en muchas especies de plantas, por ejemplo, en Dactylis (Poaceae, Santen \& Casler, 1986), Bromus inermis (Poaceae, Tan \& Dunn, 1973) y Acacia mearnsii (Fabaceae, Beck et al., 2003). Sin embargo, no se conocen antecedentes de comparaciones de este tipo en Cactáceas.

El objetivo de este estudio es relacionar las características morfo-anatómicas con los niveles de ploidía en el género Tephrocactus, mapear las características morfo-anatómicas de la epidermis y tejidos subyacentes en la filogenia del género y reconstruir los estados ancestrales a fin de comprender la historia evolutiva de las características anatómicas del grupo.

\section{Materiales y Métodos}

\section{Área de estudio y material vegetal}

Todas las plantas utilizadas en este estudio se encuentran cultivadas en el cactario del Instituto Multidisciplinario de Biología Vegetal, de la Facultad de Ciencias Exactas, Físicas y Naturales, UNC y los ejemplares se encuentran depositados en el Museo Botánico de Córdoba (CORD), Argentina. Se seleccionaron ejemplares de 15 taxones del género, además de cuatro especies estudiadas como grupo externo, para el análisis del mapeo de caracteres. Los datos de colección se muestran en la Tabla 1.

\section{Anatomía de la epidermis y tejidos subyacentes de} tallo

Para la observación de la anatomía se hicieron cortes transversales y longitudinales a mano alzada (datos en Tabla 2). Para la observación superficial de la epidermis se realizó la técnica de raspado (D’Ambrogio de Argüeso, 1986). El material se tiñó con azul astral en solución acuosa al $0,5 \%$ por cinco minutos y luego de enjuagar con agua, se realizó el montaje semi-permanente con glicerina acuosa al 50\%. Las observaciones se hicieron bajo microscopio óptico Olympus BX61 y los preparados fueron fotografiados con la cámara acoplada Olympus DP71, procesados con el software de adquisición Olympus DP controler. El procedimiento se realizó en al menos un individuo de cada taxón, y en cada caso, se fotografiaron cinco campos de cada muestra (pseudoréplicas).

Para clasificar los estomas, se siguieron las propuestas de Dilcher (1974) y Prabhakar (2004). Para el análisis cuantitativo, se determinaron las siguientes variables epidérmicas: frecuencia estomática (número de estomas por $\mathrm{mm}^{2}$ ), frecuencia de células epidérmicas propiamente dichas (número de células por $\mathrm{mm}^{2}$ ), y tamaño de los estomas (longitud de las células oclusivas, $\mu \mathrm{m})$. Estos parámetros se obtuvieron utilizando el software libre ImageJ (http://rsbweb.nih.gov/ij), y con ellos se calculó el índice estomático (I.E.) según la fórmula de Stace (1965), I.E.= (frecuencia de estomas / frecuencia de estomas + frecuencia de células epidérmicas propiamente dichas) X 100 . Por último, se realizó una descripción cualitativa del sistema dérmico y tejidos subyacentes en corte transversal, para algunas de las especies estudiadas (T. alexanderi, T. articulatus, T. geometricus y $T$. paediophilus).

\section{Análisis de datos}

Las variables morfo-anatómicas fueron comparadas estadísticamente mediante pruebas de análisis de la varianza (ANOVA), o su equivalente no paramétrico Kruskall Wallis, seguido de un análisis de comparación de medias (Tukey, $\mathrm{P}<0,05$ ). Se realizaron regresiones lineales para analizar 
Tabla 1. Taxones de Tephrocactus y géneros afines estudiados y sus datos de colección. Todos los taxones fueron coleccionados en la Argentina (provincia, departamento, localidad, colector y número). Al final de la tabla, en gris oscuro, se señalan las especies estudiadas como grupo externo.

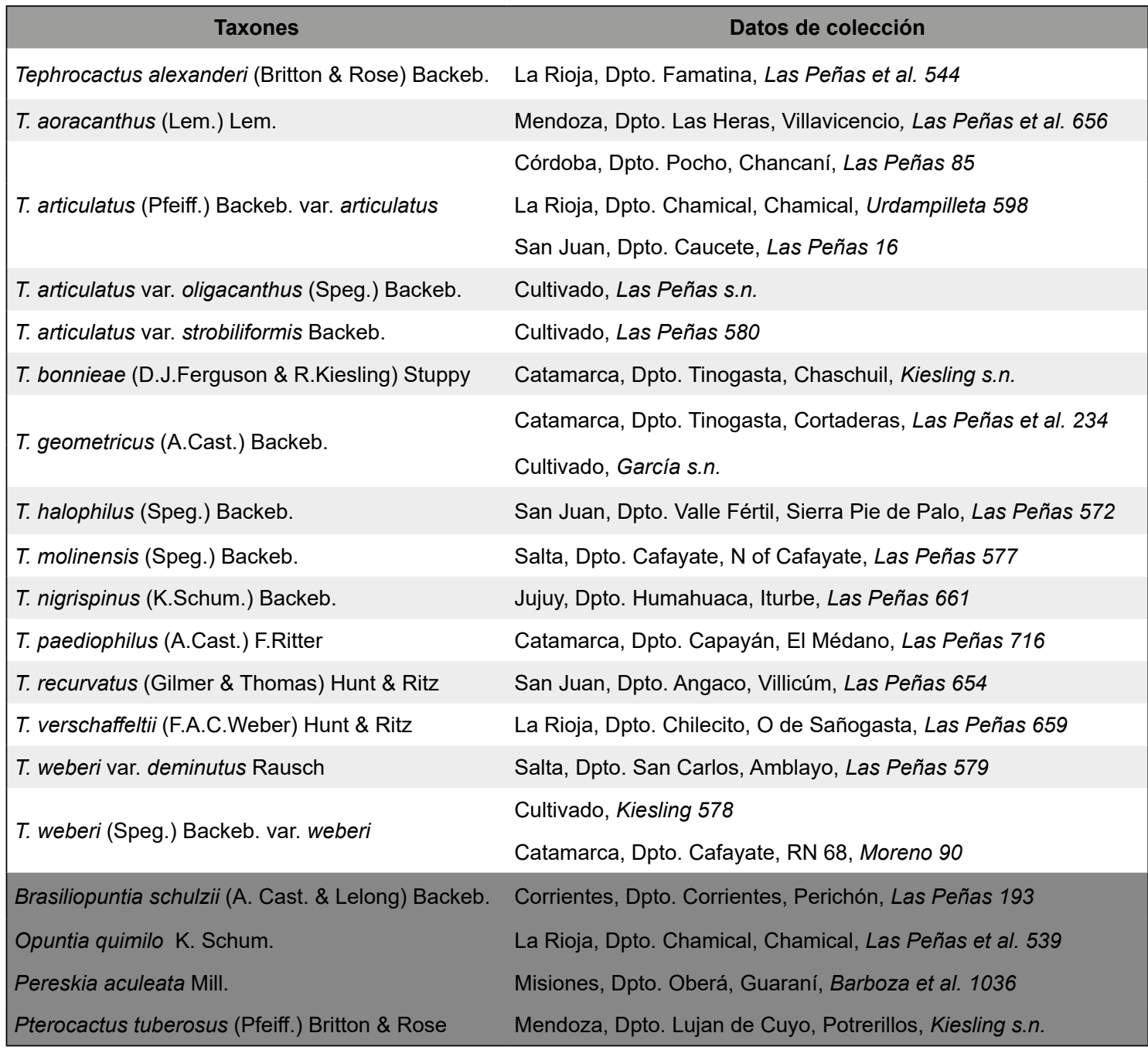

la relación entre el número cromosómico (2n), y las variables morfo-anatómicas. Los especímenes analizados son los mismos que se estudiaron en el trabajo de Las Peñas et al. (2019), por lo que se usaron los datos citogenéticos obtenidos allí para las comparaciones estadísticas. Los análisis estadísticos se realizaron utilizando el software INFOSTAT (Di Rienzo et al., 2017).

\section{Mapeos de caracteres morfo-anatómicos}

Los estados de caracteres morfo- anatómicos fueron reconstruidos para los ancestros según el criterio de máxima verosimilitud (modelo Mk1, en el que todos los cambios son igualmente probables) mediante Mesquite (Maddison \& Maddison, 2018), usando como datos de entrada el consenso de mayoría obtenido por Las Peñas et al. (2019). Se codificaron los caracteres morfo-anatómicos cuantitativos: longitud de los estomas $(\mu \mathrm{m})$ y frecuencia de células epidérmicas propiamente dichas (número/ $\mathrm{mm}^{2}$ ); además del carácter cualitativo: presencia/ausencia de drusas (Tabla 2). Los análisis bayesianos se realizaron con cuatro 
Tabla 2. Variables morfo-anatómicas cuantitativas de la epidermis de taxones de Tephrocactus y grupos externos. Media \pm error estándar para frecuencia estomática, frecuencia de células epidérmicas propiamente dichas, índice estomático (frecuencia estomática / frecuencia estomática + frecuencia de células epidérmicas propiamente dichas $X 100)$ y longitud de los estomas. Las letras diferentes indican diferencias significativas $(p<0,05)$ entre los taxones del género. Drusas $(0=$ ausencia; $1=$ presencia $), 2 n=$ números cromosómicos obtenidos de Las Peñas et al., 2019. * especies no incluida en los análisis morfoanatómicos. Al final de la tabla, en gris oscuro, se señalan las especies estudiadas como grupo externo.

\begin{tabular}{|c|c|c|c|c|c|c|}
\hline Taxones & $\begin{array}{l}\text { Frec. estomática } \\
\qquad\left(\mathrm{n}^{\circ} / \mathrm{mm}^{2}\right)\end{array}$ & $\begin{array}{l}\text { Frec. de cél. } \\
\text { epidérmicas prop. } \\
\text { dichas }\left(\mathrm{n}^{\circ} / \mathrm{mm}^{2}\right)\end{array}$ & $\begin{array}{c}\text { Índice } \\
\text { estomático }\end{array}$ & $\begin{array}{l}\text { Long. estomas } \\
\qquad(\mu \mathrm{m})\end{array}$ & Drusas & $2 n$ \\
\hline Tephrocactus alexanderi & $51,75 \pm 6,49$ cde & $2618,18 \pm 77,54$ def & $1,96 \pm 0,28 \mathrm{ab}$ & $25,36 \pm 0,50$ ab & 1 & 22 \\
\hline T. aoracanthus & $26,57 \pm 2,62^{a}$ & $876,92 \pm 12,23$ & $2,95 \pm 0,32$ bcde & $54,38 \pm 1,73^{e}$ & 1 & 242 \\
\hline $\begin{array}{l}\text { T. articulatus var. } \\
\text { articulatus }\end{array}$ & $48,95 \pm 4,32$ cd & $1821,91 \pm 68,11$ bcd & $2,58 \pm 0,16 \mathrm{bcd}$ & $34,87 \pm 0,40^{c}$ & 1 & 88 \\
\hline $\begin{array}{l}\text { T. articulatus var. } \\
\text { oligacanthus }\end{array}$ & $29,37 \pm 2,62 a b$ & $1286,71 \pm 16,40^{a}$ & $2,24 \pm 0,21 b c$ & $50,00 \pm 1,17^{d}$ & 1 & 88 \\
\hline $\begin{array}{l}\text { T. articulatus var. } \\
\text { strobiliforme }\end{array}$ & $47,55 \pm 5,14$ cde & $1525,87 \pm 15,22 a b c$ & $3,02 \pm 0,32$ cde & $33,76 \pm 0,57^{c}$ & 1 & 77 \\
\hline T. bonniae & $44,76 \pm 2,80$ bcd & $1433,57 \pm 19,66{ }^{a b}$ & $3,03 \pm 0,20$ cde & $25,53 \pm 0,96 a b$ & 0 & 44 \\
\hline T. geometricus & * & * & * & * & 1 & 22 \\
\hline T. halophilus & $72,73 \pm 4,74$ de & $2953,85 \pm 63,73$ ef & $2,41 \pm 0,17 b c$ & $26,87 \pm 0,82$ ab & 1 & 22 \\
\hline T. molinensis & $22,38 \pm 1,40^{a}$ & $1970,63 \pm 42,73$ bcde & $1,12 \pm 0,06^{a}$ & $28,88 \pm 0,80^{a b}$ & 1 & 44 \\
\hline T. nigrispinus & $41,96 \pm 2,21$ bcd & $1492,31 \pm 19,73$ ab & $2,74 \pm 0,16^{\mathrm{bcd}}$ & $29,51 \pm 0,92^{b}$ & 1 & 44 \\
\hline T. paediophilus & $30,77 \pm 1,71$ ab & $823,78 \pm 14,06^{a}$ & $3,60 \pm 0,20 \mathrm{de}$ & $48,36 \pm 1,19 d$ & 1 & 319 \\
\hline T. recurvatus & $86,71 \pm 4,74{ }^{e}$ & $2181,82 \pm 36,47$ cdef & $3,81 \pm 0,16^{e}$ & $27,29 \pm 1,10 a b$ & 1 & 44 \\
\hline T. vershaffeltii & $36,36 \pm 2,62 \mathrm{abc}$ & $1553,85 \pm 21,37 a b c$ & $2,29 \pm 0,17 b c$ & $25,80 \pm 0,80 a b$ & 1 & 22 \\
\hline T. weberi var. deminutus & $41,96 \pm 2,21 \mathrm{bcd}$ & $3959,44 \pm 23,76^{f}$ & $1,05 \pm 0,05^{a}$ & $24,78 \pm 0,899^{a}$ & 1 & 22 \\
\hline T. weberi var. weberi & $34,27 \pm 3,68 b c$ & $2976,22 \pm 110,37$ ef & $1,15 \pm 0,12^{a}$ & $26,37 \pm 0,44$ ab & 1 & 44 \\
\hline Brasiliopuntia schulzii & $18,18^{*}$ & $1408,39^{*}$ & $1,28^{*}$ & $30,24^{*}$ & 1 & 22 \\
\hline Opuntia quimilo & $36,36^{*}$ & $1650,35^{*}$ & $2,16^{*}$ & $37,98^{*}$ & 1 & 22 \\
\hline Pereskia aculeata & $15,38^{*}$ & $2727,27^{*}$ & $0,55^{\star}$ & $27,48^{*}$ & 1 & 22 \\
\hline Pterocactus tuberosus & $33,56^{*}$ & $752,45^{*}$ & $4,26^{*}$ & $31,91^{*}$ & 0 & 44 \\
\hline
\end{tabular}

cadenas independientes de Markov acoplada a Metrópolis Monte Carlo (MCMC), estos fueron implementados para analizar estados discretos y continuos respectivamente. En la Tabla 2, se encuentran las especies de Tephrocactus y también las especies analizadas para enraizar los árboles y poder recostruir los estados ancestrales para cada uno de los caracteres morfo-anatómicos.

\section{Resultados}

Características morfo-anatómicas de la epidermis y tejidos subyacentes

Cortes transversales: Se observó que la superficie de los tallos de Tephrocactus está cubierta por una epidermis de grosor variable, siendo particularmente gruesa en $T$. paediophilus y $T$. aoracanthus, mientras que en $T$. weberi y $T$. verschaffeltii es muy 
delgada. En estos cortes fue posible distinguir los siguientes estratos: una cutícula delgada con una fina capa de cera epicuticular, por debajo, una a varias capas de células epidérmicas propiamente dichas isodiamétricas, interrumpidas regularmente por estomas que se ubican en depresiones (Fig. 1). De esta forma, los mismos quedan apenas por debajo del nivel de la epidermis como se observó en $T$. alexanderi (Fig. 1C, epidermis uniestratificada), o profundamente hundidos como en T. geometricus (Fig. 1D). Este último, mostró una epidermis pluriestratificada, con tres a cuatro capas de células, que al verse interrumpida por profundas depresiones complicó su análisis en vista superficial con el método usado en este trabajo. Por su parte, T. articulatus (Fig. 1A) y T. paediophilus (Fig. 1B), presentaron un estado intermedio, con una epidermis biestratificada y los estomas se encuentran hundidos pero son parte de la epidermis. Por último, se observó una hipodermis pluriestratificada, de naturaleza colenquimatosa. En la mayoría de los casos, la misma triplicó o cuadruplicó el grosor de la epidermis, excepto en $T$ geometricus, que presentó ambas capas de aproximadamente el mismo grosor. En todos los casos, la hipodermis se vio interrumpida por cámaras subestomáticas, que la atraviesan en toda su extensión, llegando hasta el clorénquima (Fig. 1).

Además, en la hipodermis se encontraron cristales tipo drusas (Fig. 2). Estas se encontraron inmediatamente por debajo de la epidermis y no se desprendieron de la misma durante el proceso de raspado. La forma, cantidad y disposición fueron variables, en la mayoría de los casos se ubicaron regularmente, excepto en $T$. articulatus var. strobiliforme, donde parecen agruparse bajo los estomas (Fig. 2C). Lo opuesto sucedió en $T$. paediophilus, donde las drusas se observaron de gran tamaño y muy abundantes, cubriendo prácticamente toda la superficie, excepto bajo los estomas (Fig. 2F). También fueron muy abundantes en $T$. articulatus var. articulatus (Fig. 2B) y en $T$. nigrispinus (Fig. 2E), en cambio fueron pocas en $T$. verschaffeltii y se encontraron dispersas de manera aleatoria (Fig. 2D). Por último, en T. weberi var. weberi, se observó una gran cantidad de drusas más pequeñas, dispersas al azar (Fig. 2A). La única especie en la que no se observaron estos cristales fue $T$. bonniae.
Cortes paradermales de tallo: En estos se observó la epidermis en vista superficial (Figs. 3-4). Las células de los complejos estomáticos de todas las especies se distribuyeron aleatoriamente. El complejo estuvo formado por las células oclusivas con forma de riñón y las células acompañantes o subsidiarias. En la mayoría de los casos se encontraron dos pares de estas células acompañantes (dos células a cada lado de las oclusivas), excepto en $T$. halophilus, que mostró tres pares de células subsidiarias (tres células a cada lado de las oclusivas, Fig. 3D). Anatómicamente, el género presentó estomas paralelocíticos, característicos de la familia. Las células epidérmicas propiamente dichas tendieron a ser isodiamétricas, con las paredes anticlinales casi rectas en la mayoría de los casos. Sólo $T$. verschaffeltii (Fig. 3C) y T. nigrispinus (Fig. 3G) presentaron células con las paredes anticlinales más o menos onduladas.

\section{Variables morfo-anatómicas cuantitativas}

En la Tabla 2 se sintetizan, para los taxones estudiados, los valores de frecuencia estomática, frecuencia de células epidérmicas propiamente dichas, índice estomático y longitud de los estomas. Se encontraron diferencias significativas $(p<0,0001)$ en la frecuencia estomática entre los diferentes taxones. La misma varió desde 22 estomas/ $\mathrm{mm}^{2}$ en T. molinensis hasta 87 estomas $/ \mathrm{mm}^{2}$ en T. recurvatus. Por otra parte, la frecuencia de células epidérmicas propiamente dichas, que es una medida indirecta del tamaño de las mismas, varió desde 820 células $/ \mathrm{mm}^{2}$ en T. paediophilus y $T$. aoracanthus, hasta 4000 células $/ \mathrm{mm}^{2}$ en $T$. weberi var. deminutus. El índice estomático, que relaciona las frecuencias estomáticas y la de células epidérmicas propiamente dichas, tomó valores desde uno en $T$. weberi var. deminutus, T. molinensis y $T$. weberi var. weberi, hasta cuatro en $T$. recurvatus. Por último, la longitud de los estomas mostró también gran variabilidad, con valores que van desde $25,36 \mu \mathrm{m}$ en $T$. alexanderi hasta 54,38 $\mu \mathrm{m}$ en $T$. aoracanthus. Las cuatro variables morfo-anatómicas cuantitativas medidas mostraron diferencias significativas $(p<0,05)$ entre los taxones analizados (Tabla 2). 

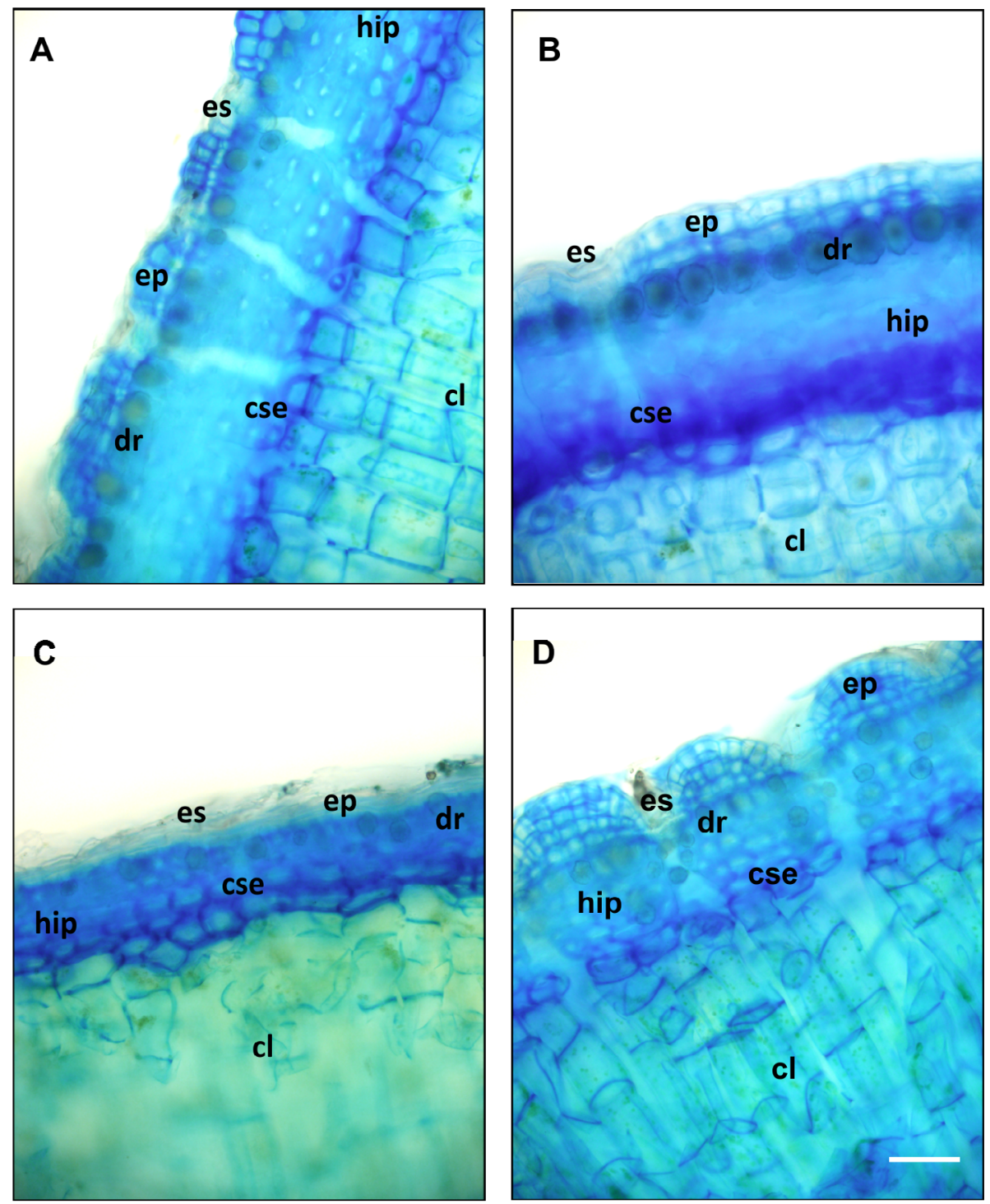

Fig. 1. Epidermis y tejidos subyacentes de Tephrocactus en corte transversal. A: T. articulatus. B: T. paediophilus. C: T. alexanderi. D: T. geometricus. Abreviaturas: ep: epidermis, hip: hipodermis, es: estoma, cse: cámara subestomática, dr: drusas, cl: clorénquima. Escala $=100 \mu \mathrm{m}$. Todas las fotos a la misma escala.

Relación entre las variables morfo-anatómicas y los niveles de ploidia

Las variables morfo-anatómicas se relacionaron con el número cromosómico $(2 \mathrm{n})$ para todos los taxones de Tephrocactus analizados mediante regresiones lineales simples. La frecuencia de células epidérmicas propiamente dichas y el número cromosómico se relacionaron significativamente y de manera negativa. Esto significa que los individuos con mayor número $2 \mathrm{n}$ de cromosomas presentaron las frecuencias de células más bajas, o lo que es lo mismo, células más grandes (Fig. 5). Por otra parte, la longitud de los estomas y el número cromosómico se relacionaron significativamente y de manera positiva, lo que implica que los individuos con mayor cantidad de cromosomas tienen los estomas más grandes (Fig. 5). Las otras variables morfo-anatómicas (frecuencia estomática 

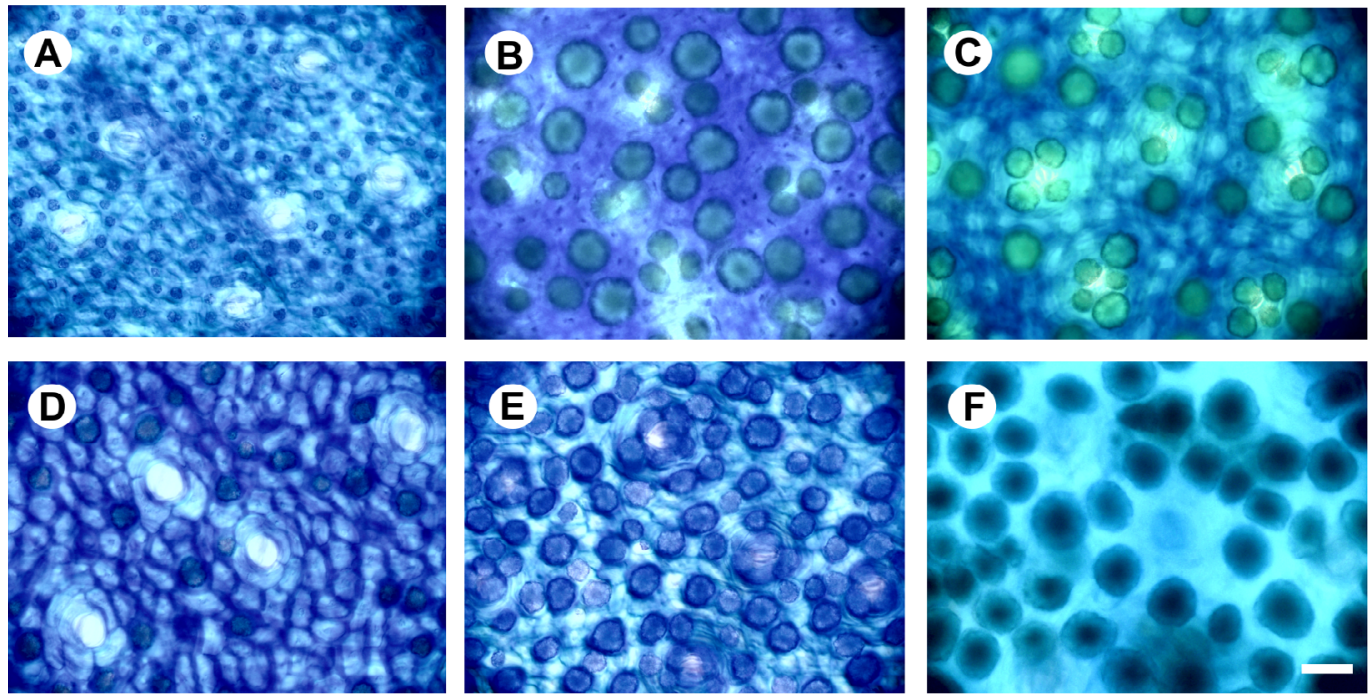

Fig. 2. Drusas en Tephrocactus. A: T. weberi var. diminutus. B: T. articulatus var. articulatus. C: T. articulatus var. strobiliforme. D: T. verschaffeltii. E: T. nigrispinus. F: T. paediophilus. Escala $=50 \mu \mathrm{m}$. Todas las fotos a la misma escala.
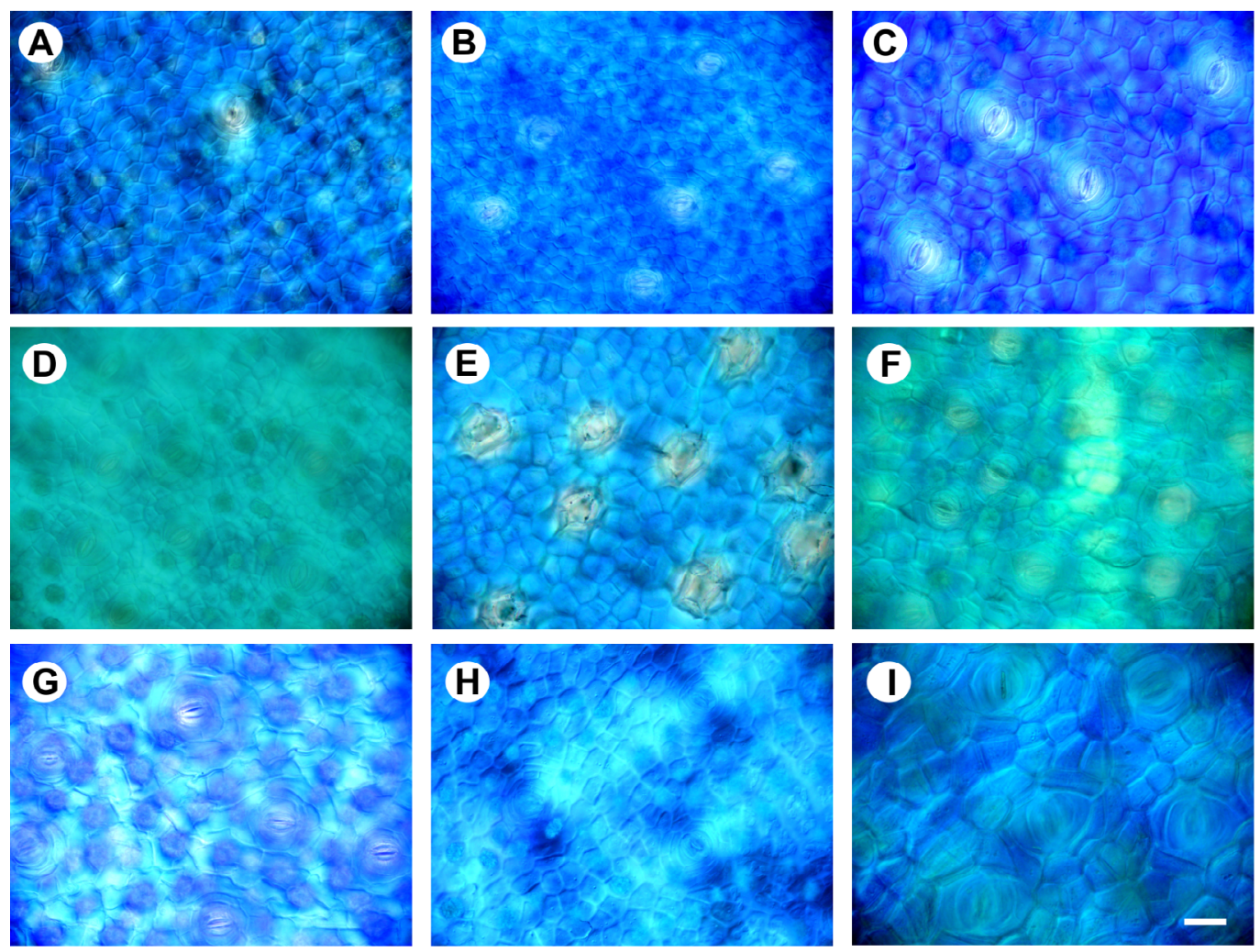

Fig. 3. Epidermis de Tephrocactus en vista superficial (con DIC). A: T. weberi var. weberi. B: T. weberi var. deminutus. C: T. verschaffeltii. D: T. halophilus. E: T. bonniae. F: T. recurvatus. G: T. nigrispinus. H: T. molinensis. I: $T$. aoracanthus. Escala $=50 \mu \mathrm{m}$. Todas las fotos a la misma escala. 

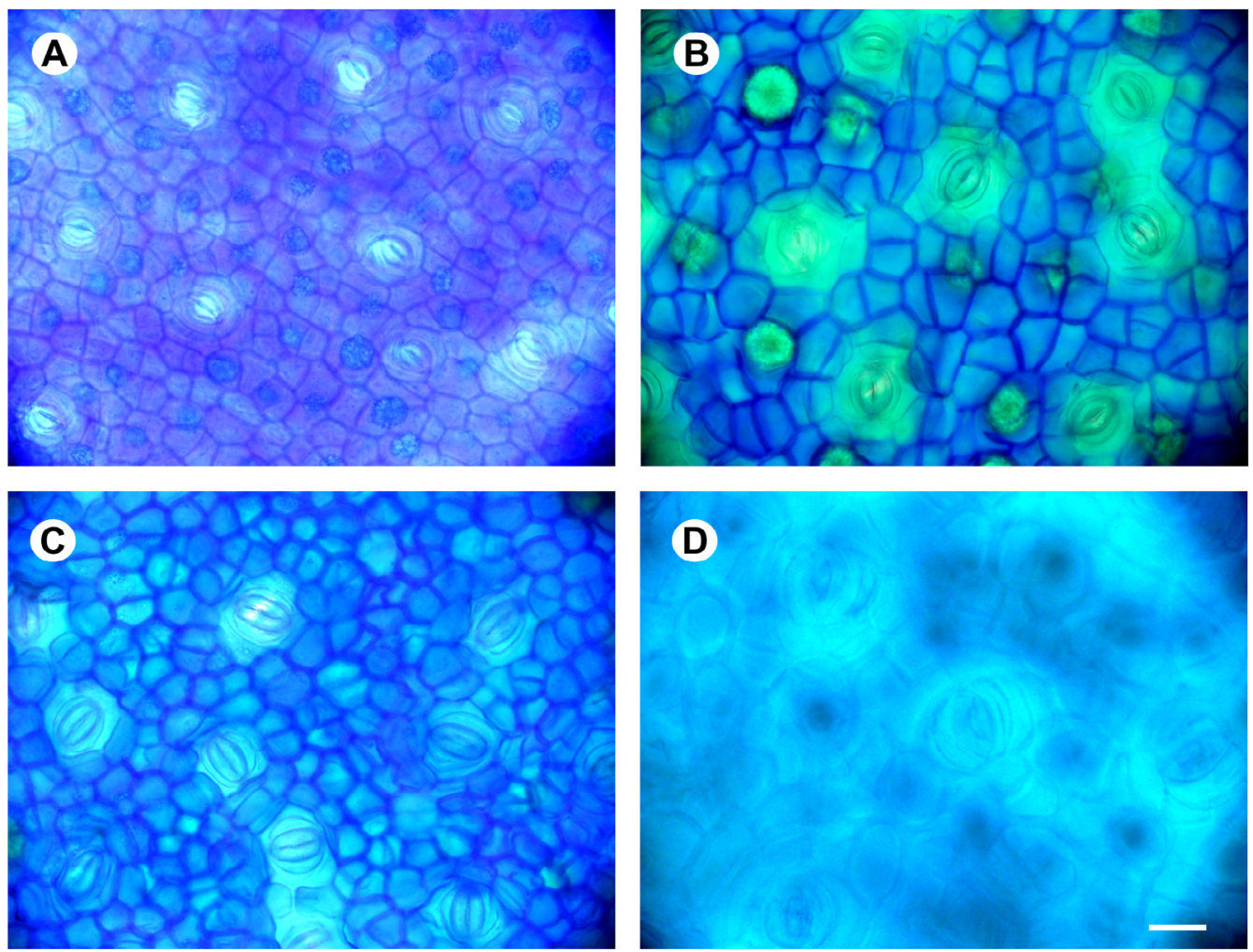

Fig. 4. Epidermis de Tephrocactus en vista superficial. A: T. alexanderi. B: T. articulatus var. strobiliforme. C: T. articulatus var. articulatus. D: T. paediophilus. Escala $=50 \mu \mathrm{m}$. Todas las fotos a la misma escala.

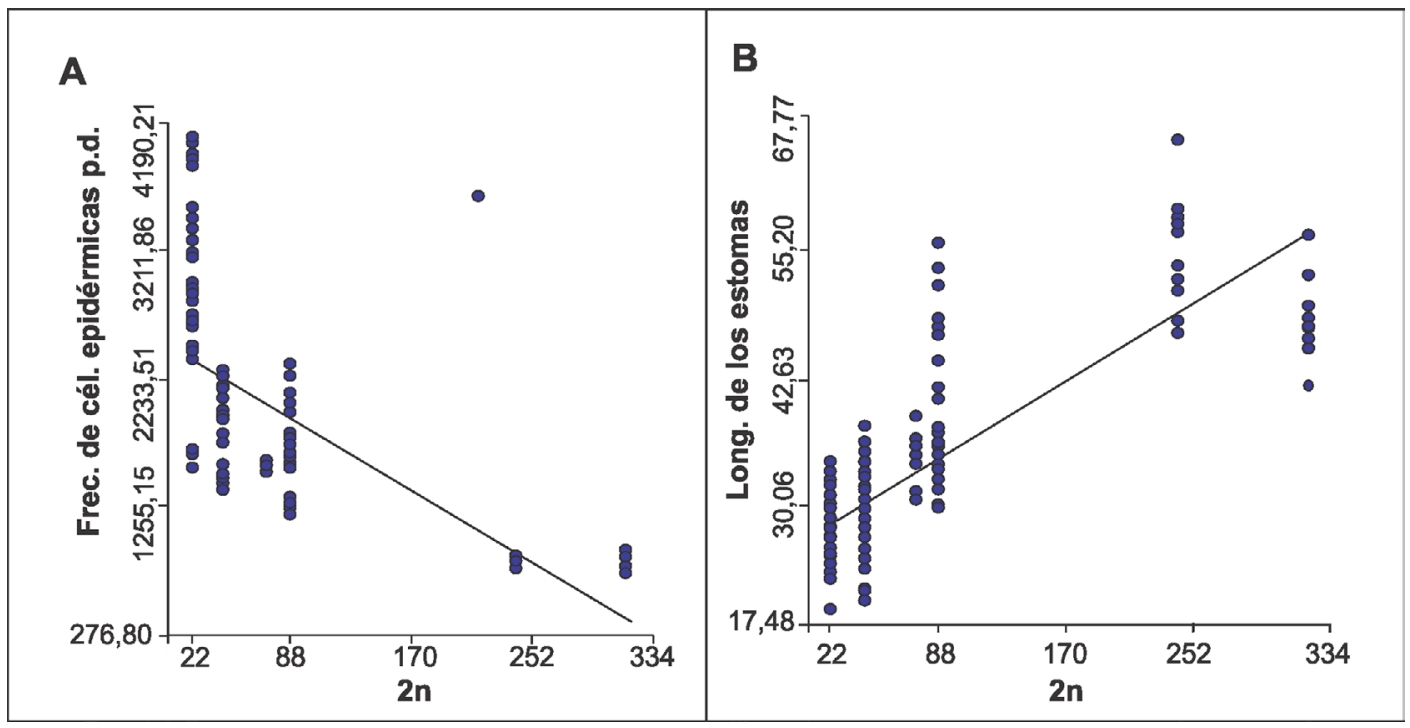

Fig. 5. Regresiones entre las variables morfo-anatómicas y los niveles de ploidía de Tephrocactus. A: Relación entre la frecuencia de células epidérmicas propiamente dichas y el número cromosómico $2 \mathrm{n}(\mathrm{N}=$ $\left.85 ; R^{2}=0,42 ; p<0,0001\right)$. B: Relación entre la longitud de los estomas y el número cromosómico $2 n(N=$ $\left.170 ; R^{2}=0,66 ; p<0,0001\right)$. 


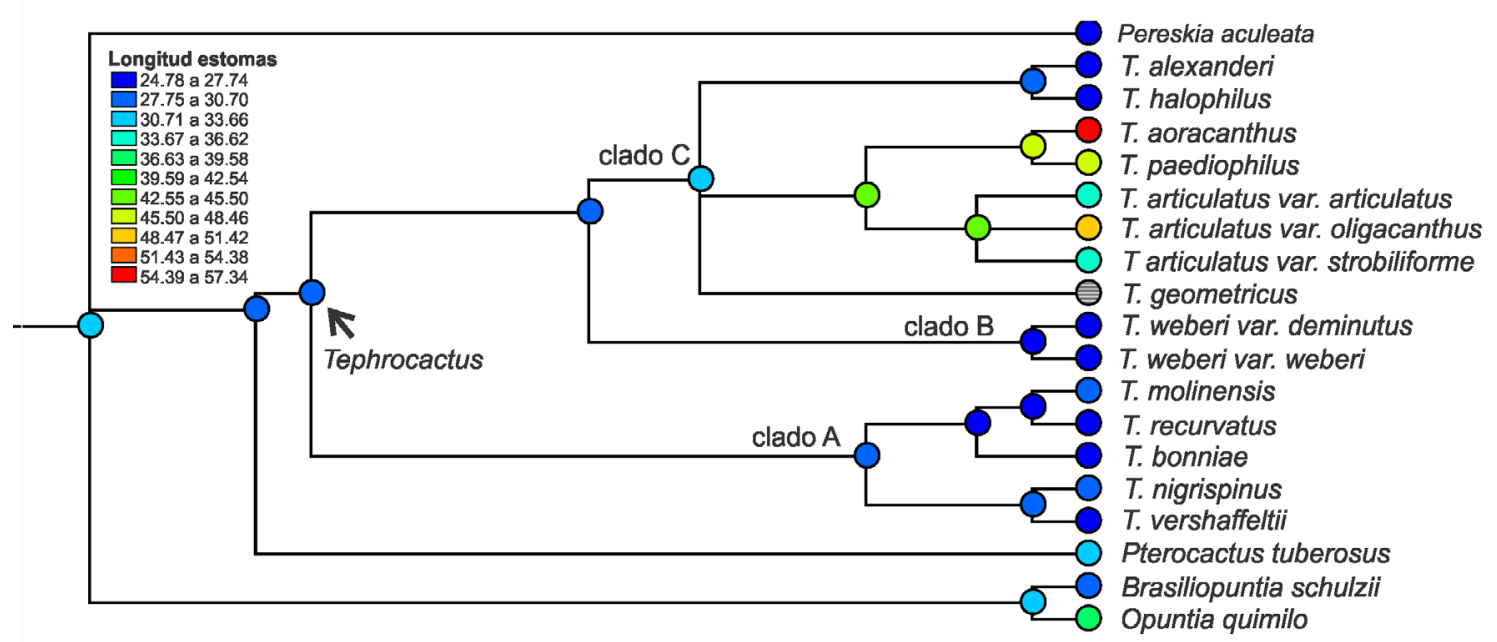

Fig. 6. Reconstrucción del estado ancestral para la longitud de los estomas en un árbol consenso del género Tephrocactus. Los colores indican diferentes estados del carácter.

e índice estomático) no mostraron relaciones estadísticamente significativas con el nivel de ploidía.

\section{Mapeo de los caracteres morfo-anatómicos}

Se mapearon cuatro caracteres morfoanatómicos (longitud de los estomas, frecuencia de células epidérmicas propiamente dichas, frecuencia estomática y presencia de drusas) en la filogenia del género obtenida por Las Peñas et al. (2019). La longitud estomática (Fig. 6) presentó los valores más elevados en el clado $\mathrm{C}$ que incluye a los taxones con mayores niveles de ploidía. El clado basal A de Tephrocactus (T. verschaffeltii, T. nigrispinus, $T$. bonniae, $T$. recurvatus y $T$. molinensis) agrupó a las especies con longitudes estomáticas menores. Estas presentaron valores similares al ancestro del género $(24,78$ a $27,74 \mu \mathrm{m})$. La reconstrucción para el estado ancestral de la frecuencia de células epidérmicas propiamente dichas (Fig. 7) mostró valores intermedios de células por $\mathrm{mm}^{2}$, entre 2035,95 y 2997,34. T. weberi var. diminutus presentó una autapomorfía para este carácter. Por último, con respecto al mapeo de la presencia/

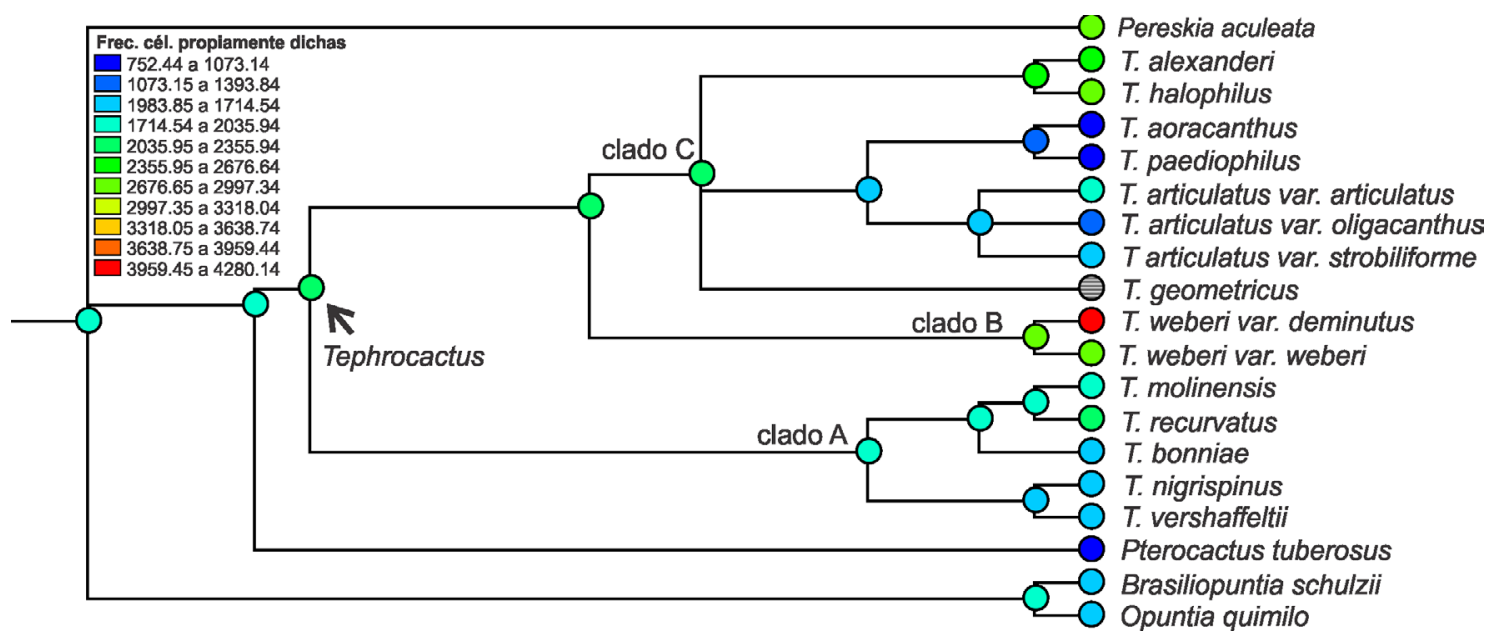

Fig. 7. Reconstrucción del estado ancestral para la frecuencia de células epidérmicas propiamente dichas en un árbol consenso del género Tephrocactus. Los colores indican diferentes estados del carácter. 


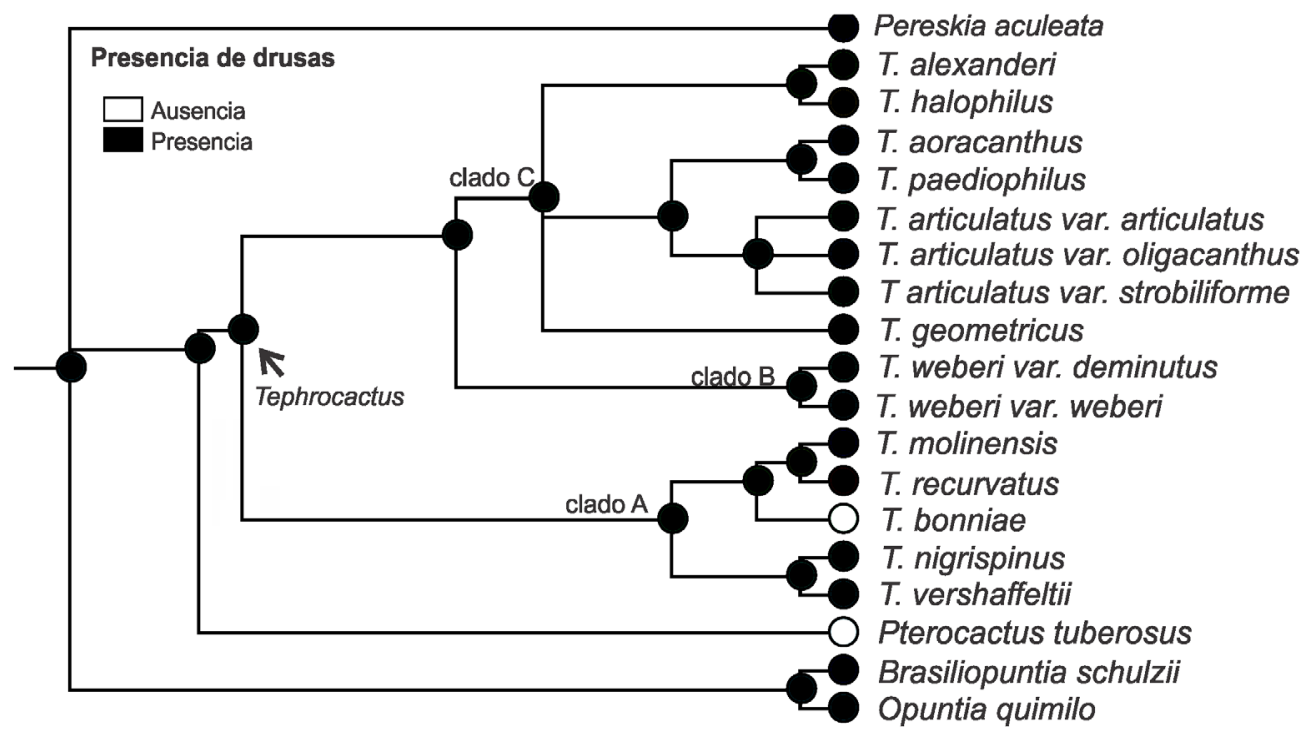

Fig. 8. Reconstrucción del estado ancestral para la presencia/ausencia de drusas en un árbol consenso del género Tephrocactus.

ausencia de drusas en la hipodermis (Fig. 8) se puede observar que el ancestro común al género presentaba drusas. Además, se pudo observar una homoplasia para este carácter en las especies $T$. bonniae y Pterocactus tuberosus, debido a una pérdida secundaria del mismo. A partir de lo antes expuesto, se puede deducir que el ancestro para el género Tephrocactus habría tenido las siguientes características morfo-anatómicas: una longitud estomática pequeña, una frecuencia de células epidérmicas propiamente dichas intermedia y presencia de drusas.

\section{Discusión y Conclusiones}

Características morfo-anatómicas de la epidermis y tejidos subyacentes

La cutícula provee una importante interfase para las interacciones entre la planta y el ambiente. Junto a las ceras epicuticulares reduce la transpiración al proporcionar una barrera hidrofóbica y reflejar la luz solar, al tiempo que reduce la temperatura de la planta. Por lo tanto, la supervivencia de la misma en ambientes hostiles puede depender de la presencia de la cutícula (Upadhyaya \& Furness, 1994). La existencia de una cutícula delgada es una característica común en la familia
Cactaceae (Nobel, 2002), y todos los ejemplares de Tephrocactus (Opuntioideae) estudiados aquí no fueron la excepción. Lo mismo ocurre para la mayoría de especies de Cactoideae estudiadas por Loza-Cornejo \& Terrazas (2003).

Un tallo de cactus típico generalmente tiene una epidermis uniestratificada (una capa de células) con células cuadradas o rectangulares en sección transversal (Nobel, 2002). La forma de las células coincide con lo observado en los taxones de Tephrocactus analizados. Sin embargo, se encontraron individuos con epidermis formadas por dos capas de células, como $T$. articulatus y $T$. paediophilus (Fig. 1A- B) y otros con epidermis pluriestratificadas, como T. geometricus (Fig. 1D). Así, el número de capas de células epidérmicas, podría tener valor taxonómico para el género, estas epidermis pluriestratificadas tendrían su origen en la protodermis, aunque no se han realizado estudios ontogenéticos. Por otro lado, la presencia de estomas paralelocíticos, ubicados en depresiones de la epidermis, es una característica común en la familia (Anderson, 2001; Nobel, 2002; Faigón et al., 2011; Guerra \& Medri, 2015). La aparición de estomas ubicados en criptas o depresiones, según LozaCornejo \& Terrazas (2003), es bastante frecuente, y puede interpretarse como una adaptación que reduce la transpiración, ya que implica la 
formación de una cámara supraestomática. La ocurrencia de hipodermis en especies xerófilas suculentas es una característica común (Morris et al., 1996), y particularmente en Cactaceae está bien representada (Vázquez-Sánchez et al., 2016). En los ejemplares de Tephrocactus analizados, la misma es pluriestratificada y en la mayoría de los casos triplica o cuadruplica el grosor de la epidermis. La hipodermis actúa restringiendo la pérdida de agua, permitiendo una absorción más eficiente de la radiación fotosintética activa, protegiendo el clorénquima de la radiación alfa y beta (Gibson \& Nobel, 1986; Kalashnyk et al., 2016) y disminuyendo la temperatura del tallo (Gibson \& Nobel, 1986). Según Terrazas \& Arias (2002), en Cactaceae, el grosor de la hipodermis puede variar dentro de la especie de acuerdo con las condiciones en que se encuentra la planta.

La mayoría de los cactus acumulan cristales que pueden ser prismáticos, en forma de drusas y raramente aciculares (Nobel, 2002). La forma, el tamaño y la naturaleza química de los mismos (principalmente oxalatos de calcio), presentan en Cactaceae una mayor diversidad que en cualquier otra familia de plantas (Gibson \& Nobel, 1986). En todos los taxones de Tephrocactus estudiados, excepto en T. bonniae, se encontraron abundantes drusas en la hipodermis. Éstas son especialmente comunes en la capa exterior de la hipodermis de todas las especies de Opuntioideae (Gibson \& Nobel, 1986), pero también se encuentran presentes en las Cactoideas norteamericanas estudiadas por Loza-Cornejo \& Terrazas (2003) y en cactus epífitos como Lepismium cruciforme (Guerra \& Medri, 2015). Los cristales en general tendrían funciones como soporte mecánico, evitando el colapso cuando el tejido pierde la suculencia y defensa ante la herbivoría (Cenizo et al., 2013). Además, podrían ayudar a controlar el equilibrio iónico en la planta, regular la presión osmótica, la absorción y la reflexión de la luz (Soffiatti \& Angyalossy, 2007; Kalashnyk et al., 2016).

En estudios anatómicos de los estomas de cactus, la mayoría de los autores han encontrado que el par de células oclusivas se encuentra flanqueado por una o dos (rara vez más) células, llamadas subsidiarias o acompañantes. Estas se encuentran a cada lado de las células oclusivas y paralelas a ellas (Gibson \& Nobel, 1986). Los complejos estomáticos de las especies de Tephrocactus estudiadas aquí, pertenecen a este tipo, llamados paracíticos o paralelocíticos, lo que parece ser una característica común en Opuntioideae (Faigón et al., 2011). En cuanto al número de células acompañantes, se encontró que la mayoría de las especies de Tephrocactus posee dos células subsidiarias ubicadas a cada lado de las células oclusivas. Excepto en T. halophilus donde se observaron tres células acompañantes a cada lado de las células oclusivas.

Las paredes anticlinales de las células epidérmicas pueden ser rectas o sinuosas, sin embargo, se desconoce si las paredes sinuosas ofrecen alguna ventaja selectiva. La presencia de paredes anticlinales con ondulaciones en Cactaceae podría permitir que las células epidérmicas se expandan y contraigan cuando la planta pierde o absorbe agua (HerreraMartínez et al., 2015). Otros autores postulan que la diferencia entre las formas rectas y sinuosas podría estar más relacionada con la madurez de la planta, ya que los tejidos jóvenes tienen paredes sinuosas (Loza-Cornejo \& Terrazas, 2003). Hernández et al. (2007) observaron que las paredes anticlinales de las células epidérmicas eran sinuosas en la posición apical de las ramas en Myrtillocactus geometrizans; y que, en la región media, donde las células eran más maduras, las paredes anticlinales eran en su mayoría rectas. Para los análisis realizados en Tephrocactus, se tomaron muestras del tercio medio de los tallos, encontrándose en la mayoría de los casos células epidérmicas con paredes anticlinales rectas. Sólo T. verschaffeltii (Fig. 3C) y T. nigrispinus (Fig. 3G) presentaron células con las paredes más o menos onduladas.

En cuanto a las variables morfo-anatómicas cuantitativas, las xerofitas suculentas tienen menos estomas por unidad de área, y su tamaño es significativamente mayor, en comparación con las xerofitas no suculentas (Fahn \& Cutler, 1992). Particularmente, los tallos de los cactus suculentos tienen, usualmente, de 15 a 70 estomas por milímetro cuadrado, un valor menor que el encontrado en hojas de otras eudicotiledóneas, quienes generalmente poseen más de 100 estomas por milímetro cuadrado (Gibson \& Nobel, 1986). Los ejemplares de Tephrocactus mostraron frecuencias estomáticas que van desde poco más de 22 estomas por milímetro cuadrado en $T$. molinensis hasta casi 87 estomas por milímetro cuadrado en T. recurvatus (Fig. 6), valores acordes 


\section{Ivana Di Dio et al. - Morfo-anatomía en Tephrocactus y su correlación con niveles de ploidía}

con los antecedentes. La longitud de los estomas varió desde 25,36 $\mu \mathrm{m}$ en $T$. alexanderi hasta 54,38 $\mu \mathrm{m}$ en $T$. aoracanthus. Estos resultados también son acordes a los encontrados por otros autores en otras cactáceas (Hernández et al., 2007; Faigón et al., 2011; Herrera-Martínez et al., 2015). Los valores de índice estomático, por su parte, también fueron similares a los encontrados por autores como Guerra \& Medri (2015) y Herrera-Martínez et al. (2015) en la familia. Estos autores reportaron, además, diferencias en la cantidad de estomas e índice estomático, de acuerdo a condiciones de cultivo diferentes o distintos ambientes en que crecen los cactus estudiados.

Relación entre las variables morfo-anatómicas y los niveles de ploidía

La poliploidía junto con la hibridación entre las especies son unas de las principales causas de especiación en Cactaceae (Grant \& Grant, 1980; Pinkava, 2002; Las Peñas et al., 2017, 2019). Los poliploides se han estudiado por sus diferencias morfológicas, fisiológicas y de desarrollo (Madlung, 2013). Particularmente, la longitud de las células oclusivas de los estomas se ha usado a menudo como marcador morfológico para identificar los niveles de ploidía en muchas especies de plantas, por ejemplo, en Dactylis (Poaceae, Santen \& Casler, 1986), Bromus inermis (Poaceae, Tan \& Dunn, 1973) y Acacia mearnsii (Fabaceae, Beck et al., 2003). Sin embargo, no se conocen antecedentes de comparaciones de este tipo en Cactáceas. En este trabajo se encontró una relación significativa y positiva entre el nivel de ploidía de los ejemplares de Tephrocactus y el tamaño de sus estomas y células epidérmicas propiamente dichas. Esto se asemeja a los resultados de Melaragno et al. (1993), quienes reportaron un mayor tamaño de las células epidérmicas y particularmente de los estomas en poliploides de Arabidopsis (Brassicaceae). Cabe recordar que, en el presente estudio, el tamaño de las células epidérmicas propiamente dichas se midió indirectamente, usando como parámetro la frecuencia de dichas células (cantidad por $\mathrm{mm}^{2}$ ). Es por ello, que se observó una regresión lineal simple negativa entre dicha frecuencia y el número cromosómico. Sin embargo, esta relación fue menos significativa que la hallada para la longitud de los estomas. Además, la longitud de las células oclusivas de los estomas es un método conveniente y confiable para la clasificación de plantas con diferentes niveles de ploidía (Aryavand et al., 2003; Rêgo et al., 2011). Los resultados de este trabajo muestran que hay diferencias en la longitud de las células oclusivas en diferentes taxones de Tephrocactus relacionadas con su nivel de ploidía, como ha sido observado en otros trabajos (Aryavand et al., 2003; Rêgo et al., 2011). Por último, es importante destacar que este estudio es el primero en realizar una correlación entre los niveles de ploidía y caracteres morfo-anatómicos en cactus. Sería interesante poder analizar otros géneros de Opuntioideae con el objeto de determinar si se mantiene esta relación.

\section{Mapeo de los caracteres morfo-anatómicos}

En el presente estudio, resultaron informativos los mapeos de la longitud de los estomas, la frecuencia de células epidérmicas propiamente dichas, y la presencia de drusas en la hipodermis. La longitud estomática y la frecuencia de células epidérmicas propiamente se correlacionó con la ploidía (ver arriba) y los taxones poliploides se encontraron en el clado $\mathrm{C}$, mientras que el clado A tempranamente diversificado agrupó a las especies con los estomas más pequeños y menor frecuencia de células epidérmicas propiamente (es decir, células de menor tamaño), siendo estos los taxones diploides. Un caso particular es el mostrado por T. weberi var. diminutus (diploide), que presentó una elevada frecuencia de células epidérmicas propiamente dichas (entre 3959,45 y 4280,14 células por $\mathrm{mm}^{2}$ ). Esto constituye una autapomorfía del clado B, es decir un carácter exclusivo.

Por último, el mapeo de la presencia/ausencia de drusas en la hipodermis mostró que el ancestro común al género presentaba drusas, al igual que la mayoría de los miembros actuales, y como se ha reportado de forma aislada en varios taxones de la familia Cactaceae (Mauseth, 2005). Sólo $T$. bonniae no las presenta, característica que comparte con el miembro externo Pterocactus tuberosus. De este modo, el carácter "ausencia de drusas" representó una homoplasia (o convergencia) para dichas especies. Esto podría estar relacionado con que ambas especies se comportan como geófitas, perdiendo sus tallos durante el invierno o en ambientes hostiles. En esos casos, sobreviven de manera semisubterránea, a expensas de sus raíces napiformes (Kiesling, 1975 y 1984; Las Peñas et al., 2019). 
El mapeo de los caracteres morfo-anatómicos de la epidermis de los taxones de Tephrocactus, indicaría que el ancestro del grupo tendría estomas pequeños, una frecuencia de células epidérmicas propiamente dichas intermedia y drusas en su hipodermis. Estos datos en conjunto con los datos obtenidos por Las Peñas et al., (2019), nos permitieron reconstruir la historia evolutiva de los taxones, es decir, que la diversificación del género se asocia con tres eventos de poliploidía (Las Peñas et al., 2019), lo que podría estar asociado a la reproducción vegetativa que permite en las especies mantener altos niveles de ploidía $2 \mathrm{x}=22$ hasta 29 . Por otra parte, las características morfo-anatómicas de cada taxón estarían asociadas a su nivel de ploidía, lo cual permite usar las características citogenéticas, morfológicas (Las Peñas et al., 2019) y morfo-anatómicas como un carácter taxonómico en el grupo.

\section{Contribución de los AUTORES}

Todos los autores diseñaron y realizaron la investigación y participaron en la escritura del manuscrito. MLLP coleccionó el material de campo y consultó herbarios.

\section{Agradecimientos}

Los autores agradecemos el financiamiento a la Secretaría de Ciencia y Tecnología, Universidad Nacional de Córdoba (SeCyT-UNC), al Fondo para la Investigación Científica y Tecnológica (FONCYT) y alConsejo Nacional de Investigaciones Científicas y Técnicas (CONICET). A la técnica de microscopía del IMBIV Alejandra Trenchi y Adriana Pérez que nos ayudaron con la obtención de las imágenes en el microscopio y las técnicas histológicas.

\section{Bibliografía}

ALMIRÓN, M. G. \& E. MARTÍNEZ CARRETERO. 2013. Tephrocactus aoracanthus (Lem.) Lem. Reproducción sexual y clonal en un cactus dominante del desierto hiperárido argentino. J. Prof. Assoc. Cactus Dev. 15: 20-31.
ANDERSON, E. F. 2001. The cactus family. Portland: Timber Press. Estados Unidos.

ARYAVAND, A., B. EHDAIE, B. TRAN \& J. G. WAINES. 2003. Stomatal frequency and size differentiate ploidy levels in Aegilops neglecta. Genet. Resour. Crop Evol. 50: 175-182. https://doi.org/10.1023/A:1022941532372

BALDWIN, S. J. \& B. C. HUSBAND. 2013. The association between polyploidy and clonal reproduction in diploid and tetraploid Chamerion angustifolium. Molec. Ecol. 22: 1806-1819.

https://doi.org/10.1111/mec. 12217

BECK, S. L., R. W. DUNLOP \& A. FOSSEY. 2003. Stomatal length and frequency as a measure of ploidy level in black wattle, Acacia mearnsii (de Wild). Bot. J. Linn. Soc. 141: 177-181. https://doi.org/10.1046/j.1095-8339.2003.00132.x

BRAVO HOLLIS, H. \& L. SCHEINVAR. 1999. El interesante mundo de las cactáceas. Fondo de Cultura Económica, UNAM. México.

CENIZO, V. J., M. B. MAZZOLA, B. M. C. MOLÁS \& A. G. KING. 2013. Características morfológicas y anatómicas de las plántulas de Trichocereus candicans (Cactaceae). Bol. Soc. Arg. Bot. 48: 453-464. https://doi.org/10.31055/1851.2372.v48.n3-4.7546

D'AMBROGIO DE ARGÜESO, A. 1986. Manual de Técnicas en Histología Vegetal. Ed. hemisferio sur, Argentina.

DI FULVIO, T. E. 1976. Observaciones en epidermis de Notocactus y Wigginsia (Cactaceae). Kurtziana 9: 63-80.

DI RIENZO, J. A., F. CASANOVES, M. G. BALZARINI, L. GONZALEZ, M. TABLADA \& C. W. ROBLEDO. 2017. InfoStat versión 2017. Grupo InfoStat, FCA, Universidad Nacional de Córdoba, Argentina.

DILCHER, D. L. 1974. Approaches to the identification of angiosperm leaf remains. Bot. Rev. 40: 1-157. https://doi.org/10.1007/BF02860067

FAHN, A. \& D. F. CUTLER. 1992. Xerophytes. Encyclopedia of Plant Anatomy-Gebrüder Borntraeger, D-1000 Berlin, Alemania.

FAIGÓN, A., B. G. GALATI, S. ROSENFELDT \& R. KIESLING. 2011. Epidermal characters of Pterocactus (Opuntioideae, Cactaceae). Haseltonia 16: 57-66.

https://doi.org/10.2985/1070-0048-16.1.57

GIBSON, A. C. \& P. S. NOBEL 1986. The cactus primer. Harvard University Press. Estados Unidos. https:// doi.org/10.4159/harvard.9780674281714 
GUERRA, A. \& C. MEDRI. 2015. Diferenciação morfoanatômica de Lepismium cruciforme (Vell.) Miq. (Cactaceae) do dossel e do sub-bosque. SaBiosRev. Saúde e Biol. 10: 43-51.

GRANT, V. \& K. A. GRANT. 1980. Clonal microspecies of hybrid origin in the Opuntia lindheimeri group. Bot. Gaz.141: 101-106. https://doi.org/10.1086/337129

HERNÁNDEZ, M., T. TERRAZAS, A. D. ALVARADO \& M. L. CAVAZOS. 2007. Los estomas de Myrtillocactus geometrizans (Mart. Ex. Pfeiff.) console (Cactaceae): variación en su área de distribución. Rev. Fitotecnia Mex. 30: 235-240.

HERNÁNDEZ-HERNÁNDEZ, T., H. M. HERNÁNDEZ, J. A. DE-NOVA, R. PUENTE, L. E. EGUIARTE \& S. MAGALLÓN. 2011. Phylogenetic relationships and evolution of growth form in Cactaceae (Caryophyllales, Eudicotyledoneae). Amer. J. Bot. 98: 44-61. https://doi.org/10.3732/ajb.1000129

HERRERA-MARTÍNEZ, V., L. RIOS-HERNÁNDEZ, C. GARCIDUEÑAS-PIÑA, A. LARA-IBARRA, A. ADABACHE-ORTIZ, R. E. SORIA-GUERRA, E. PÉREZ-MOLPHE-BALCH \& J. F. MORALESDOMÍNGUEZ. 2015. Effect of culture conditions on stomatal density and stomatal index in four cactus species. Haseltonia 20: 43-51. https://doi.org/10.2985/026.020.0108

HUNT, D., N. TAYLOR \& C. GRAHAM. 2006. The new cactus lexicon: descriptions and illustrations of the cactus family. Milborne Port: David Hunt Books.

KALASHNYK, H., N. NUZHYNA \& M. GAIDARZHY. 2016. Anatomical and morphological features of seedlings of some Cactoideae Eaton (Cactaceae Juss.) species. Acta Agrobot. 69: 1-11. https://doi.org/10.5586/aa.1697

KIESLING, R. 1975. Los géneros de Cactaceae de Argentina. Bol. Soc. Arg. Bot. 16: 197-227.

KIESLING, R. 1984. Estudios en Cactaceae de Argentina: Maihueniopsis, Tephrocactus y géneros afines (Opuntioideae). Darwiniana 25: 171-215.

LAS PEÑAS, M. L., L. OAKLEY, N. C. MORENO \& G. BERNARDELLO. 2017. Taxonomic and cytogenetic studies in Opuntia ser. Armatae (Cactaceae). Botany 95: 101-120. https://doi.org/10.1139/cjb-2016-0048

LASPEÑAS,M.L.,R.KIESLING\&G.BERNARDELLO. 2019. Phylogenetic reconstruction of the genus Tephrocactus (Cactaceae) based on molecular, morphological, and cytogenetical data. Taxon 68: 714-730. https://doi.org/10.1002/tax.12092

LOZA-CORNEJO, S. \& T. TERRAZAS 2003. Epidermal and hypodermal characteristics in North American
Cactoideae (Cactaceae). J. Plant Res. 116: 27-35. https://doi.org/10.1007/s10265-002-0066-2

MADDISON, W. P. \& D. R. MADDISON. 2018. Mesquite: a modular system for evolutionary analysis. Version $3.51 \mathrm{http}: / / \mathrm{www} . \mathrm{mesquiteproject.org}$.

MADLUNG, A. 2013. Polyploidy and its effect on evolutionary success: old questions revisited with new tools. Heredity 110: 99-104. https://doi.org/10.1038/hdy.2012.79

MANDUJANO, M., J. GOLUBOV \& J. REYES. 2002. Lo que usted siempre quiso saber sobre las cactáceas y nunca se atrevió a preguntar. Biodiversitas 40: 4-7.

MAUSETH, J.D. 2005. Anatomical features, other than wood, in subfamily Opuntioideae (Cactaceae). Haseltonia 2005: 113-125. https://doi.org/10.2985/10700048(2005)11[113:AFOTWI]2.0.CO;2

MELARAGNO J. E., B. MEHROTRA \& A. W. COLEMAN. 1993. Relationship between endopolyploidy and cell size in epidermal tissue of Arabidopsis. Plant Cell 5: 1661-1668. https://doi.org/10.1105/tpc.5.11.1661

MORRIS, M. W., W. L. STERN \& W. S. JUDD. 1996. Vegetative anatomy and systematics of subtribe Dendrobiinae (Orchidaceae). Bot. J. Linn. Soc.120: 89-144. https://doi.org/10.1111/j.1095-8339.1996.tb00483.x NOBEL, P. S. 2002. Cacti: biology and uses. Berkeley: University of California Press. Estados Unidos.

PRABHAKAR, M. 2004. Structure, nomenclature and classification of stomata. Acta Bot. Sinica 44: 242252.

PINKAVA, D. J, M. A. BAKER, B. D. PARFITT \& M. W. MOHLENBROCK. 1985. Chromosome numbers in some cacti of western North America. Syst. Bot. 10: 471-483. https://doi.org/10.2307/2419140

PINKAVA, D.J. 2002. On the evolution of the continental North American Opuntioideae. Pp. 59-98. In: HUNT, D. \& TAYLOR, N. (eds.), Studies in the Opuntioideae (Cactaceae). Succulent Plant Research 6. Milborne Port: David Hunt Books.

RÊGO, M. D., E. R. RÊGO, C. H. BRUCKNER, F. L. FINGER \& W. C. OTONI. 2011. In vitro induction of autotetraploids from diploid yellow passion fruit mediated by colchicine and oryzalin. Plant Cell, Tissue and Organ Culture (PCTOC) 107: 451-459. https://doi.org/10.1007/s11240-011-9995-6

RITZ, C. M., J. REIKER, G. CHARLES, P. HOXEY, D. HUNT, M. LOWRY, W. STUPPY \& N. TAYLOR. 2012. Molecular phylogeny and character evolution in terete-stemmed Andean opuntias (Cactaceae- 
Opuntioideae). Molec. Phylog. Evol. 65: 668-681. https://doi.org/10.1016/j.ympev.2012.07.027

SANTEN, E. V. \& M. D. CASLER 1986. Evaluation of indirect ploidy indicators in Dactylis L. subspecies. Crop Sci. 26: 848-852. https://doi.org/10.2135/crops ci1986.0011183X002600050002x

SOFFIATTI, P. \& V. ANGYALOSSY. 2007. Anatomy of Brazilian Cereeae (subfamily Cactoideae, Cactaceae): Arrojadoa Britton \& Rose, Stephanocereus A. Berger and Brasilicereus Backeberg. Acta Bot. Bras. 21: 813-822. https://doi.org/10.1590/S0102-33062007000400006

STACE, C. A. 1965. Cuticular studies as an aid to plant taxonomy. Bull. Br. Publisher: British Museum 4: 62-63.

TAN, G. Y. \& G. M. DUNN. 1973. Relationship of stomatal length and frequency and pollen-grain diameter to ploidy level in Bromus inermis Leyss. Crop Sc. 13: 332-334. https://doi.org/10.2135/crops ci1973.0011183X001300030014x

TERRAZAS, T. \& S. ARIAS. 2002. Comparative stem anatomy in the subfamily Cactoideae. Bot. Rev. 68: 444-473. https://doi.org/10.1663/00068101(2002)068[0444:CSAITS]2.0.CO;2

UPADHAYAYA, M. K. \& N. H. FURNESS. 1994. Influence of light intensity and water stress on leaf surface characteristics of Cynoglosum officinale, Centaurea spp. and Tragopogon spp. Canad. J. Bot. 72: 1379-1386. https://doi.org/10.1139/b94-169

VÁZQUEZ-SÁNCHEZ, M., T. TERRAZAS \& S. ARIAS. 2016. Comparative morphology and anatomy of Backebergia militaris (EchinocereeaeCactaceae) cephalium. Plant Syst. Evol. 302: 245256. https://doi.org/10.1007/s00606-015-1256-4 